OPEN ACCESS

Edited by:

Arun Saini,

Texas Children's Hospital,

United States

Reviewed by:

Katherine Cashen,

Children's Hospital of Michigan,

United States

Lakshmi Raman,

University of Texas Southwestern

Medical Center, United States

*Correspondence:

J. Marco Schnater

j.schnater@erasmusmc.nl

Specialty section:

This article was submitted to

Pediatric Critical Care,

a section of the journal

Frontiers in Pediatrics

Received: 29 January 2021

Accepted: 30 March 2021

Published: 04 May 2021

Citation:

Kersten CM, Hermelijn SM,

Wijnen RMH, Tibboel D, Houmes RJM and Schnater JM (2021) Surgery in

Neonatal and Pediatric ECMO

Patients Other Than Congenital

Diaphragmatic Hernia Repair: A

10-Year Experience.

Front. Pediatr. 9:660647.

doi: 10.3389/fped.2021.660647

\section{Surgery in Neonatal and Pediatric ECMO Patients Other Than Congenital Diaphragmatic Hernia Repair: A 10-Year Experience}

\author{
Casper M. Kersten, Sergei M. Hermelijn, René M. H. Wijnen, Dick Tibboel, \\ Robert J. M. Houmes and J. Marco Schnater ${ }^{*}$ \\ Department of Pediatric Surgery and Intensive Care, Erasmus University Medical Center Sophia Children's Hospital, \\ Rotterdam, Netherlands
}

Aim of Study: The use of extracorporeal membrane oxygenation (ECMO) has increased as a result of technological developments and the expansion of indications. Relatedly, the number of patients undergoing surgery during ECMO is also rising, at least in the adult population. Little is known on surgery in children during ECMO-therapy. We therefore aimed to assess the frequencies and types of surgical interventions in neonatal and pediatric patients on ECMO and to analyze surgery-related morbidity and mortality.

Methods: We retrospectively collected information of all patients on ECMO over a 10-year period in a single tertiary and designated ECMO-center, excluding patients undergoing cardiac surgery, and correction of congenital diaphragmatic hernia. Chi-squared test and Mann-Whitney $U$ test were used to analyze data.

Main Results: Thirty-two of 221 patients (14\%) required surgery when on ECMO. Common interventions were thoracotomy (32\%), laparotomy (23\%), fasciotomy (17\%), and surgical revision of ECMO (15\%). Complications occurred in 28 cases (88\%), resulting in a $50 \%$ in-hospital mortality rate. Surgical patients had a longer ICU stay and longer total hospital stay compared to those not receiving surgery during ECMO. No significant difference in mortality was found when comparing surgical to non-surgical patients (50 vs. $41 \%$ ).

Conclusions: Approximately one in seven neonatal or pediatric patients required surgical intervention during ECMO, of whom almost 90\% developed a complication, resulting in a 50\% mortality rate. These results should be taken into account in counseling.

\footnotetext{
Keywords: extracorporeal membrane oxygenation, surgery, outcome, complications, pediatric, neonate, critical illness, post-surgical complications
}

\section{INTRODUCTION}

Extracorporeal membrane oxygenation (ECMO) has been proven to be an efficient and costeffective addition to conventional ventilator support in both children and adults (1-3). In the last decades, the use of ECMO has increased as a result of technical developments and an extension of indications, especially beyond the neonatal period. Relatedly, the number of patients undergoing 
surgery on ECMO is increasing. This increase is accompanied by higher complication rates in adults $(4,5)$. To date, complication rates and risks of surgical procedures in children on ECMO are still unknown, apart from those undergoing congenital diaphragmatic hernia $(\mathrm{CDH})$ repair $(6,7)$.

Current indications for ECMO in the neonatal and pediatric populations include preoperative stabilization, post-surgical recovery, bridge to transplantation, bridge to recovery of organ function, and emergency cardiopulmonary resuscitation, socalled ECPR (8-10). Atkinson et al. (11) reported that 19 of 135 adults (14\%) treated with ECMO underwent surgery while on ECMO in the years 1987 through 1989. Twenty-three years later, Taghavi et al. (5) reported a corresponding proportion of 269/563 (48\%); an increase possibly demonstrating the effect of the extension of indications following new techniques and more experience. Surgical intervention during ECMO has not been associated with higher mortality rates in general $(5,11)$. Nevertheless, higher incidences of hemorrhage-related complications, due to the necessary anticoagulation during ECMO, have been reported $(4,5)$. The study of Taghavi et al. (5) found a significantly higher mortality rate in patients requiring blood transfusion because of hemorrhage.

In neonatal and pediatric patients, ECMO is often used as a bridge toward elective surgery of congenital abnormalities. Well-known examples are $\mathrm{CDH}$, cardiac defects and bronchopulmonary abnormalities $(4,12-15)$. The role of ECMO in the management of $\mathrm{CDH}$ is debated and still subject of ongoing research (16). Although, clinical trials and subsequent systematic reviews have reported improved outcomes in $\mathrm{CDH}$ patients with the use of $\operatorname{ECMO}(2,17,18)$, repair of $\mathrm{CDH}$ on ECMO can lead to hemorrhage due to the necessary anticoagulation $(6,7)$. Considering this, we decided not to include correction of $\mathrm{CDH}$ in this study.

To our knowledge, outcomes of neonatal, and pediatric patients undergoing surgical procedures on ECMO have not been published so far, apart from one abstract describing a cohort of 98 neonatal and pediatric patients on ECMO, 36 of whom (37\%) underwent surgery. In-hospital mortality was not higher in the surgical group, but a longer median length of stay, a longer intensive care unit (ICU) stay and more blood transfusions were required following surgery (19). The exact complication rate of surgery on ECMO in neonatal and pediatric patients is unknown. Consequently, clinical decision making is mostly subjective and based on expert opinion rather than evidence. The aim of our study was to analyze the frequencies and types of surgical interventions in neonatal and pediatric patients on ECMO as well as the surgery-related morbidity and mortality.

\section{METHODS}

We searched our center's electronic patient database as well as the national Extracorporeal Life Support Organization (ELSO) database for patients who had received ECMO-treatment between January 2009 and January 2019 in our center. This University center is one of two neonatal and pediatric ECMO centers in the Netherlands, executing more than 30 ECMO runs each year. Data of all patients who had undergone one or more surgical intervention on ECMO-apart from insertion and removal of cannulas-were analyzed in detail. Patients undergoing $\mathrm{CDH}$ repair and cardiac surgery during ECMO represent a distinctly different population with electively planned surgery. This population was therefore found to be beyond the scope of this article and was excluded. In addition, patients undergoing surgery in another hospital were excluded due to missing data.

We collected the following information: the child's sex, gestational age at birth, and weight at start of ECMO, indication for ECMO, type of ECMO, and duration and number of ECMOruns. Indication for ECMO was categorized into ECPR and respiratory or cardiac support, broken down for neonatal $(<28$ days age) and pediatric patients ( $\geq 28$ days age), as is customary in the ELSO registry (10). Type of ECMO was categorized into veno-venous double lumen (VVDL), veno-arterial (VA), veno-venous ( $\mathrm{VV})$, a combination of types (hybrid), or multiple consecutive types (multiple).

Surgical procedures were categorized as thoracic, abdominal, and vascular. Only the surgical removal, replacement or placement of additional ECMO cannulas apart from primary installation of ECMO was counted as a surgical procedure. The number of days on ECMO elapsed at the time of the surgery was noted. Furthermore, we distinguished between therapeutic and diagnostic surgical procedures and elective vs. emergency surgery. The following outcome parameters were recorded: total length of hospital stay, total days at ICU and complications including mortality. Complications were categorized as hemorrhage, ischemia, compartment syndrome, mortality, and other. Cause of death was categorized as futility, neurological, cardiovascular, pulmonary, therapy failure, or directly related to surgery. Deaths were measured up until discharge from our center.

Perioperative anticoagulation was administered according to local protocol, which was updated in 2015. Preoperatively thrombocytes were required to be above $150 \times 10^{9} / \mathrm{L}$. Thirty minutes before start of the surgery Tranexamic acid was administered with a loading dosage of $4 \mathrm{mg} / \mathrm{kg}$ intravenously, followed by a continuous infusion of $1 \mathrm{mg} / \mathrm{kg} / \mathrm{h}$ for $24 \mathrm{~h}$ or longer, depending on the extent of post-operative hemorrhage. Before 2015 Heparin was continued during surgery to maintain an activated partial thromboplastin time (APTT) of either 5075 or $60-85 \mathrm{~s}$ depending on a normal or high thrombosis risk. After 2015 Heparin was stopped preoperatively, except when the risk of thrombosis was deemed high. Furthermore, fibrinogen levels were kept $>1 \mathrm{~g} / \mathrm{L}$ for $24 \mathrm{~h}$ after the surgical procedure $(12,20)$.

\section{Analysis}

Statistical analysis was performed using SPSS (version 25, IBM Corp., Armonk, NY, USA). Differences in medians and percentages were assessed using the Mann-Whitney $\mathrm{U}$ test for continuous variables and the $\chi^{2}$ test for categorical variables. 


\section{RESULTS}

In the 10-year study period, a total of 307 patients received ECMO-treatment in our center. Eighty-six patients were excluded; i.e., 58 (67\%) who underwent cardiac surgery, 27 (31\%) who underwent $\mathrm{CDH}$ repair, and one who underwent surgery elsewhere. Of the remaining 221 patients, 32 (14\%) underwent surgery whilst on ECMO. See Figure 1 for the corresponding flowchart.

\section{Surgery vs. No Surgery $(n=221)$}

An overview of patient and ECMO characteristics is presented in Table 1. None of the baseline characteristics (sex, gestational age at birth, and birth weight) differed significantly between the surgical and non-surgical group.

\section{ECMO Characteristics}

Age and weight at start of ECMO were significantly higher in the surgical group compared to the non-surgical group. Furthermore, surgical patients had a significantly longer duration of ECMO compared to non-surgical patients.

\section{Outcome}

Both the length of stay on the ICU and the total length of hospital stay were significantly longer for the patients who underwent surgery on ECMO. However, the in-hospital mortality was not significantly different between the surgical and non-surgical group ( 41 vs. $50 \%, p=0.327$ ). While the mortality rate during ECMO was $38 \%$ in the surgical group compared to $28 \%$ in the non-surgical group, the mortality rate after cessation of ECMO was comparable between the two groups. Both differences were not statistically significant.

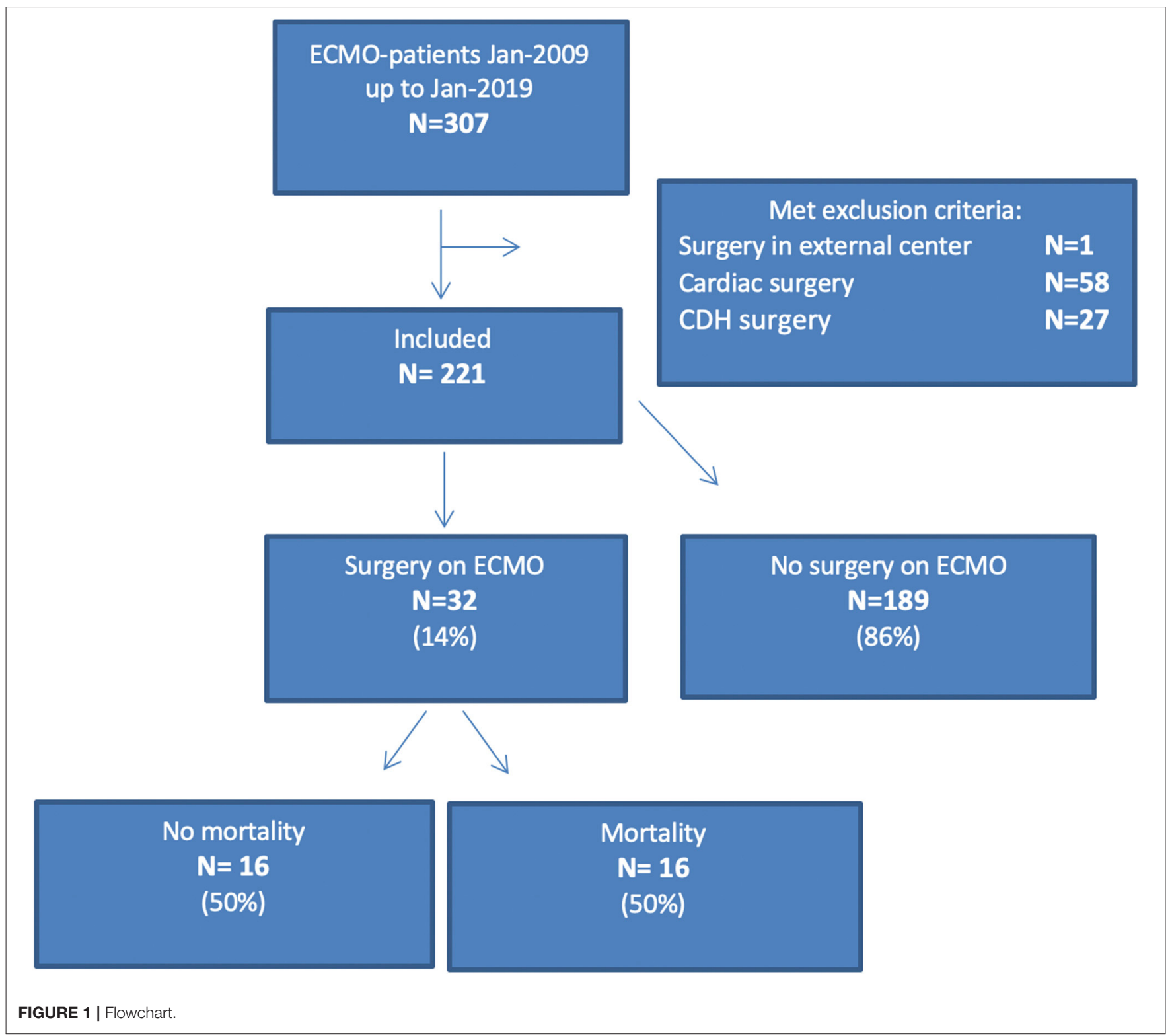


TABLE 1 | Baseline, ECMO, and outcome characteristics of surgical and non-surgical patients.

\begin{tabular}{|c|c|c|c|}
\hline & $\begin{array}{c}\text { Surgery } \\
N=32(14)\end{array}$ & $\begin{array}{l}\text { No surgery } \\
N=189(86)\end{array}$ & $P$-value \\
\hline Male & $18(56)$ & $106(62)$ & 0.986 \\
\hline Gestational age at birth & 38.79 (31.71-41.71) & 38.64 (25-42.43) & 0.531 \\
\hline Birthweight & 2700 (1800-4134) & 3225 (500-5100) & 0.356 \\
\hline Weight at start of ECMO ${ }^{\dagger}$ & $14(2.55-75)$ & $4.2(1.94-120)$ & $0.005^{\star}$ \\
\hline $\begin{array}{l}\text { Age at start of ECMO } \\
\text { categorical }^{\dagger}\end{array}$ & & & $0.005^{\star}$ \\
\hline premature $<28$ days & 0 & $9(5 \%)$ & \\
\hline At term $<28$ days & 7 (22\%) & $70(37 \%)$ & \\
\hline 28 days -2 years & $4(13 \%)$ & 47 (25\%) & \\
\hline$>2$ years & $21(66 \%)$ & 63 (33\%) & \\
\hline ECMO indication ${ }^{\dagger}$ & & & 0.144 \\
\hline Neonatal-respiratory & $6(19 \%)$ & $61(32 \%)$ & \\
\hline Neonatal-cardiac & 0 & $9(5 \%)$ & \\
\hline Neonatal-ECPR ${ }^{\ddagger}$ & $1(3 \%)$ & $7(4 \%)$ & \\
\hline Pediatric-respiratory & $13(40 \%)$ & $78(41 \%)$ & \\
\hline Pediatric-cardiac & 3 (9\%) & $9(5 \%)$ & \\
\hline Pediatric-ECPR ${ }^{\ddagger}$ & $9(28 \%)$ & 25 (13\%) & \\
\hline $\mathrm{ECMO} \mathrm{type}^{\dagger}$ & & & 0.127 \\
\hline WDL & $8(25 \%)$ & $80(42 \%)$ & \\
\hline VA & $16(50 \%)$ & 85 (45\%) & \\
\hline W & $2(6 \%)$ & $9(5 \%)$ & \\
\hline Multiple & $6(19 \%)$ & $15(8 \%)$ & \\
\hline ECMO duration ${ }^{\dagger}$ & & & $0.006^{\star}$ \\
\hline$<7$ days & 12 (38\%) & 120 (64\%) & \\
\hline $7-20$ days & $13(41 \%)$ & 55 (29\%) & \\
\hline$>20$ days & $7(22 \%)$ & $14(7 \%)$ & \\
\hline ECMO run(s) ${ }^{\dagger}$ & & & 0.707 \\
\hline 1 & 30 (94\%) & 179 (95\%) & \\
\hline 2 & $2(6 \%)$ & $6(3 \%)$ & \\
\hline 3 & 0 & $3(2 \%)$ & \\
\hline 4 & 0 & $1(1 \%)$ & \\
\hline ICU days ${ }^{\S}$ & $22(2-179)$ & $12(1-275)$ & $0.003^{*}$ \\
\hline Total hospital days & $24(0-179)$ & $15(0-300)$ & $0.023^{*}$ \\
\hline \multicolumn{4}{|l|}{ Complications } \\
\hline Compartment syndrome & $5(16 \%)$ & & \\
\hline Other & 3 (9\%) & & \\
\hline Hemorrhage & $2(6 \%)$ & & \\
\hline Ischemia leg & $2(6 \%)$ & & \\
\hline Mortality on $\mathrm{ECMO}^{\dagger}$ & $12(38 \%)$ & $53(28 \%)$ & 0.278 \\
\hline Mortality post-ECMO ${ }^{\dagger}$ & $4(13 \%)$ & $24(13 \%)$ & 0.975 \\
\hline $\begin{array}{l}\text { Complications total (including } \\
\text { mortality) }\end{array}$ & $28(88 \%)$ & & \\
\hline Total in hospital mortality & $16(50 \%)$ & 77 (41\%) & 0.327 \\
\hline Reason of death & & & 0.69 \\
\hline Futility & $8(25 \%)$ & $31(16 \%)$ & \\
\hline Neurological & $2(6 \%)$ & $8(4 \%)$ & \\
\hline Cardiovascular & $3(9 \%)$ & $19(10 \%)$ & \\
\hline Pulmonary & $3(9 \%)$ & $13(7 \%)$ & \\
\hline
\end{tabular}

(Continued)
TABLE 1 | Continued

\begin{tabular}{lccc}
\hline & $\begin{array}{c}\text { Surgery } \\
\boldsymbol{N}=\mathbf{3 2}(\mathbf{1 4})\end{array}$ & $\begin{array}{c}\text { No surgery } \\
\boldsymbol{N}=\mathbf{1 8 9}(\mathbf{8 6})\end{array}$ & $P$-value \\
\hline Therapy failure & 0 & $4(2 \%)$ \\
Surgical & 0 & $1(1 \%)$ \\
\hline
\end{tabular}

Data are reported as $n$ (\%) and median (minimum-maximum).

*Indicates significance $(p<0.05)$.

${ }^{\dagger}$ Extracorporeal membrane oxygenation.

${ }^{\ddagger}$ Extracorporeal cardiopulmonary resuscitation.

$\S$ Intensive care unit.

\section{Surgical Group}

Thirty-two (14\%) patients required surgery whilst on ECMO, 17 of whom $(53 \%)$ received more than one intervention.

\section{Types of Procedures}

Thoracic surgery accounted for $40 \%$ of procedures, followed by vascular surgery (38\%), and abdominal surgery (23\%) (Table 2). In total 53 surgical procedures were performed in these 32 patients; thoracotomy was most frequently performed $(n=17$, $32 \%)$, followed by laparotomy $(n=12,23 \%)$, fasciotomy ( $n=9$, $17 \%)$, and surgical revision of ECMO $(n=8,15 \%)$ (Figure 2).

Six out of the 17 thoracotomies were performed to obtain a lung biopsy, five for intra-thoracic hemorrhage, two for pleural effusion and two for empyema. One emergency thoracotomy was performed for a tension pneumothorax, and one for secondary closure of the thorax following a tracheal reconstruction.

Six out of the 12 laparotomies were indicated for suspicion of an abdominal compartment syndrome. In one case, a secondlook laparotomy was performed 2 days later following elevated lactic acid; this revealed extensive bowel ischemia. One patient required two laparotomy procedures on the same day because of hemorrhage 9 days after $\mathrm{CDH}$ correction. In this case ECMO was not started until 4 days after the $\mathrm{CDH}$ repair had taken place, following the development of fulminant sepsis. One laparotomy was performed for an anastomotic leakage of the bowel. The remaining two cases concerned acute laparotomy. In one case an abdominal compartment syndrome was suspected, in the other a volvulus was discovered.

Comparing survivors with non-survivors, it appeared that neither the categorical type of surgery nor the number of surgical procedures per patient was significantly different (Table 2).

\section{Indications and Planning}

Most surgical interventions were therapeutic (87\%), as opposed to $13 \%$ being diagnostic (Table 2). One diagnostic laparotomy was performed following an ECPR ECMO procedure, and this revealed a volvulus. This patient did not survive. The other six diagnostic surgical procedures were lung biopsies; three were indicated to identify the cause of pneumonia, the other three intended to investigate the cause of pulmonary hypertension. In one case, the result of the lung biopsy led to immediate cessation of therapy because of alveolar capillary dysplasia. Four out of the other five patients who underwent a lung biopsy procedure did not survive (Table 2). Death was in these cases 
TABLE 2 | Baseline, ECMO, and surgical characteristics of surgical patients.

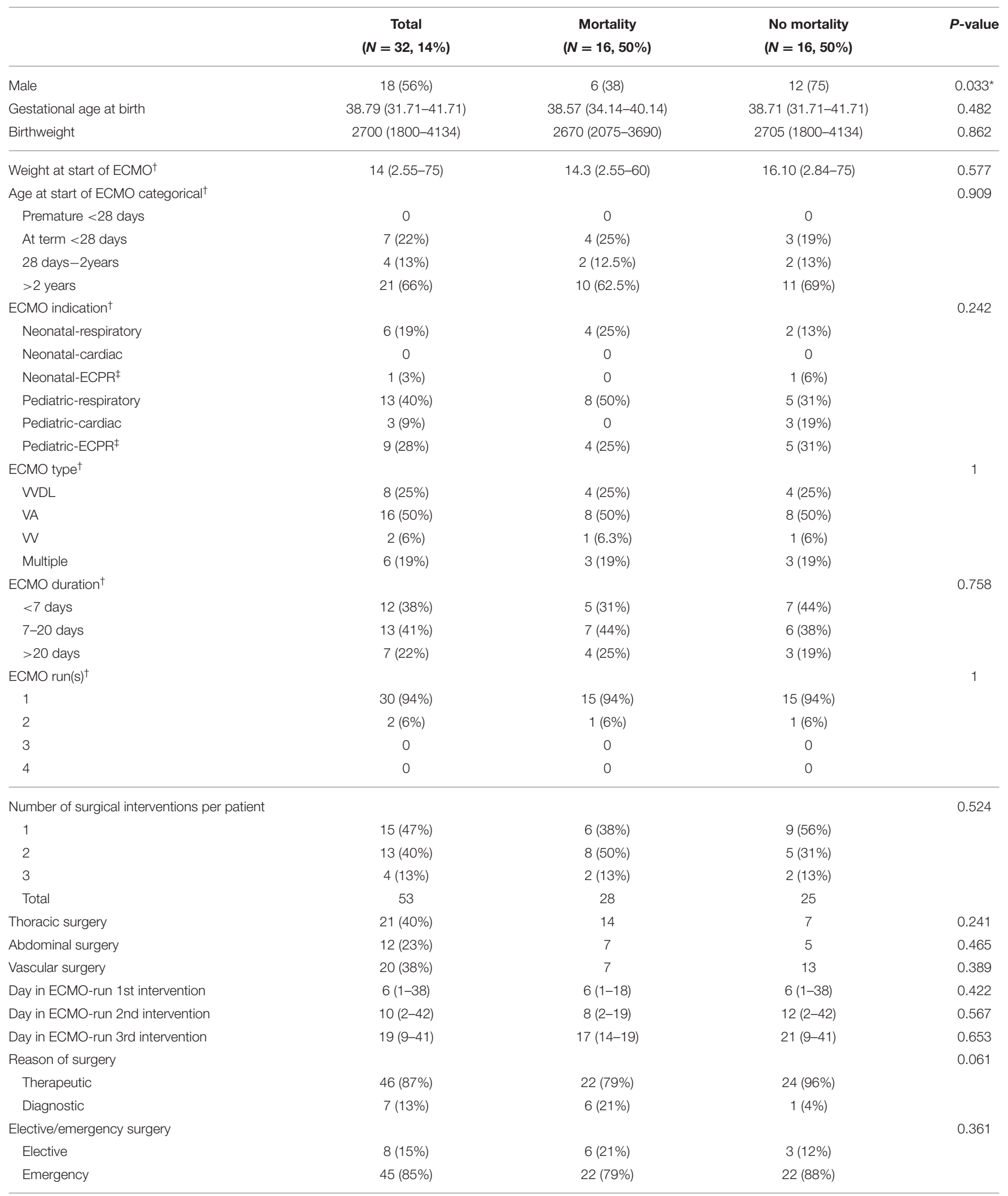

Data are reported as $n$ (\%) and median (minimum-maximum).

*Indicates significance $(p<0.05)$.

${ }^{\dagger}$ Extracorporeal membrane oxygenation.

${ }^{\ddagger}$ Extracorporeal cardiopulmonary resuscitation. 


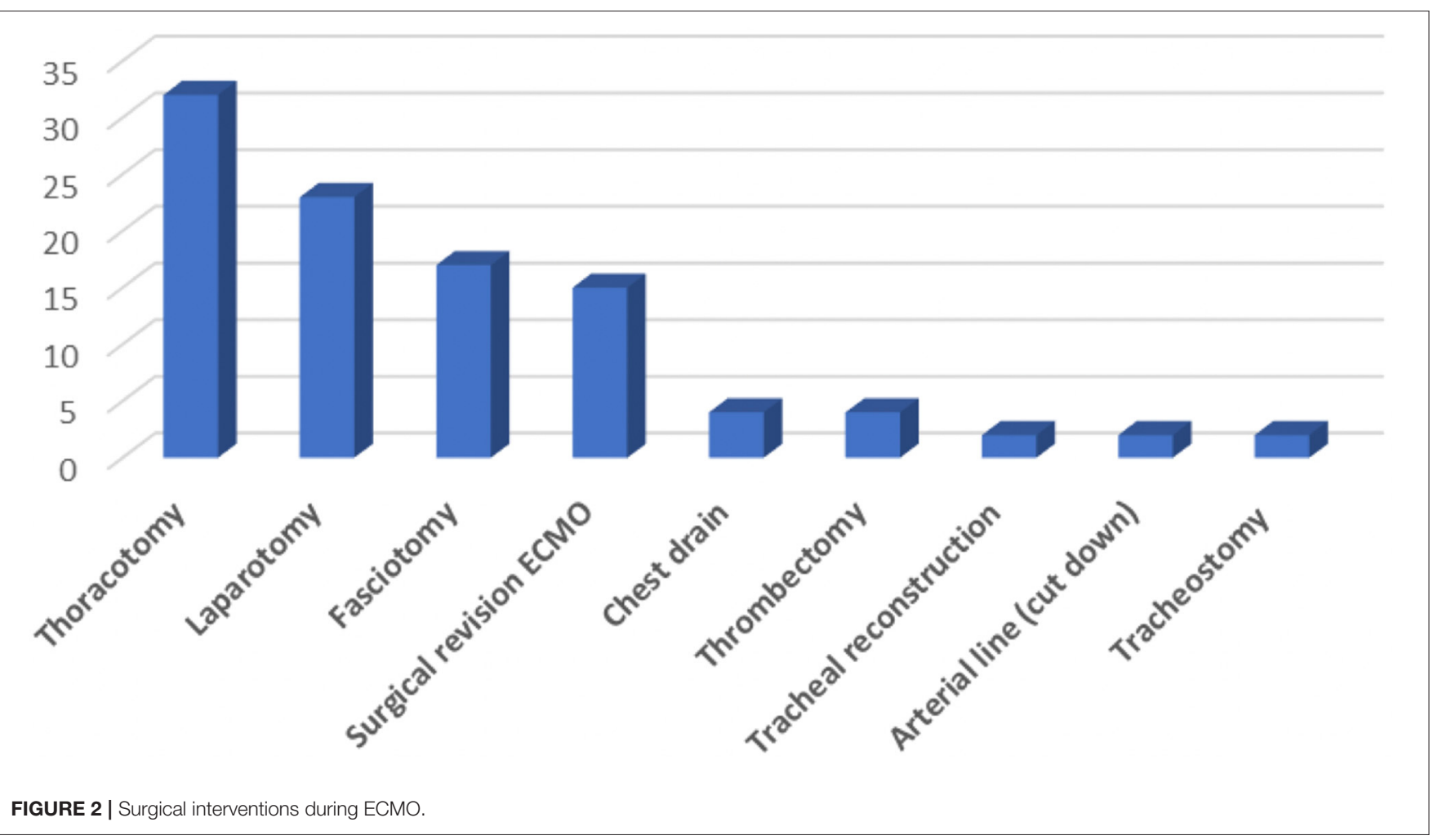

not directly related to the surgical procedure. Comparison of the mortality rate related to either diagnostic or therapeutic surgical procedures did not show a significant difference. The majority of surgical procedures took place in an emergency setting (85\%), as opposed to $15 \%$ being elective. Six of these procedures were the abovementioned diagnostic lung biopsies. In one case a tracheal reconstruction took place on ECMO due to an obstructive trachea and in one case an arterial line was placed by surgical cut down. The mortality rate was not significantly different between elective and emergency surgical cases (Table 2).

\section{Outcome}

Complications after surgery, including mortality, were seen in $88 \%$ of cases. The total in-hospital mortality was $50 \%$ in the surgical group. One quarter of deaths occurred after cessation of ECMO. Futility was the most reported reason of death (22\%), resulting in cessation of therapy after multidisciplinary consensus was reached. Pulmonary failure was noted as reason of death in 13\% of cases, and cardiovascular failure accounted for $9 \%$ of cases. Additional information concerning cause of death in the surgical cases can be found in the Supplementary Material.

\section{DISCUSSION}

To our knowledge, this is the first study describing outcomes of neonatal and pediatric patients undergoing a surgical intervention while on ECMO, apart from $\mathrm{CDH}$ repair, and cardiac surgery.
We found that $14 \%$ of the patients who received ECMOtreatment in the study period had undergone a surgical intervention while on ECMO, of whom more than half required multiple interventions. Thoracotomy was the most frequent intervention, followed by laparotomy, fasciotomy and surgical revision of ECMO cannulas. Complications occurred in $88 \%$ of surgical patients, associated with death in half of the cases. Other frequent complications included compartment syndrome and hemorrhage. The most common reason of death was futility, resulting in cessation of therapy. Patients who underwent surgery on ECMO had a significantly longer ICU stay and total hospital stay compared to non-surgical patients.

These results suggest that patients who undergo surgery while on ECMO have a higher risk of complications compared to those not operated on. In our cohort, this risk did not lead to a significantly higher in-hospital mortality in surgical patients (50 vs. $41 \% p=0.327)$. This may be related to the relatively small sample sizes, as is also seen in literature in adults (5). In the present study, one quarter of deaths in surgical patients occurred after cessation of ECMO-treatment, which demonstrates that the critical period of patients in need of surgery while on ECMO does not end with decannulation.

The proportion of neonates and children on ECMO in our cohort receiving surgery $(14 \%)$ is relatively low in comparison with studies in adults, reporting incidences from 14 to $48 \%(5,11)$. We hypothesize that this relatively low proportion is related to the relatively large group of neonates in our cohort who need ECMO for respiratory support directly post-partum, few of whom require surgical intervention during ECMO. 
When comparing the ECMO-indication in surgical and non-surgical patients, a larger proportion within the nonsurgical group is represented by neonates who are in need of ECMO due to respiratory failure (32\% non-surgical vs. $19 \%$ surgical, $p=0.144$ ). This patient group is known to have a relatively favorable prognosis (10). However, in our cohort we did not find a significant difference in mortality between the surgical and non-surgical group (50 vs. $41 \%, p$ $=0.327$. We hypothesize that this is due to the fact that the neonatal-respiratory group represents a minority within our cohort (in total 68 out of 221 patients), and therefore does not significantly influence the mortality of either of the groups.

Various studies have focused on specific surgical interventions on ECMO such as cardiac catheterization, $\mathrm{CDH}$ correction and lung biopsies $(13,20,21)$. We, however, investigated the surgical interventions in children on ECMO in general, and found a high complication rate as well as a high mortality rate in this group of patients. These findings can help improve the quality of counseling.

We searched the ELSO-registry but could not identify data on surgical interventions during ECMO. Though, complications including surgical site hemorrhage, cannulation site hemorrhage, and compartment syndrome were reported, numbers of surgical procedures appear not to be documented systematically (10). As we found that in our center approximately one in seven neonatal and pediatric patients on ECMO undergoes surgery-associated with a distinctly high complication rate-we advocate for the systematic registration of surgical interventions during ECMO in the future. Centralized registration will possibly lead to new insights and thereby influence clinical practice.

The retrospective nature of this study accounts for the possibility of missing data. The quality of data was especially poor concerning coagulation complications and transfusions in the perioperative period. Due to the large portion of missing data, analysis of these parameters was not possible. Colleagues Erdem et al. described coagulation complications on ECMO, however the relationship of these complications to surgical interventions during ECMO was not further analyzed in this study (22).

Follow-up was limited to either death or first hospital discharge after ECMO-treatment; we did not inventory whether complications had occurred thereafter. IJsselstijn et al. already stressed the importance of multidisciplinary long-term follow-up with a standardized approach, which is now being implemented in our center (23). Even though our cohort stems from the largest neonatal and pediatric ECMO-center in the Netherlands, we found it to be too small and heterogeneous for a clinically significant prediction model. In order to achieve a cohort fit for a prediction model, a multi-center study design will be necessary in order to include a sufficient number of patients. Large multicenter studies have reported high rates of complications due to either bleeding or thrombosis, warranting future studies exploring new coagulation strategies during ECMO $(24,25)$. Likewise, future multi-center studies focusing on surgical procedures during ECMO could lead to identification of possible predictive variables for surgical outcome. ECMO-treatment is an evolving field of medical practice in which new instruments and techniques are frequently introduced. Consequently, it is plausible that during the 10 years of inclusion in the present study ECMO techniques, practice and the supportive care have changed, although, recent results suggest that the transition from roller to centrifugal pump techniques has not significantly influenced outcome (22).

In conclusion, approximately one in seven neonatal and pediatric patients required a surgical intervention during ECMOtreatment, $88 \%$ of them developed complications. In-hospital mortality after surgery on ECMO was 50\%, which was not significantly higher than in non-surgical patients. These results should be taken into account in counseling.

\section{DATA AVAILABILITY STATEMENT}

The original contributions presented in the study are included in the article/Supplementary Material, further inquiries can be directed to the corresponding author/s.

\section{ETHICS STATEMENT}

The studies involving human participants were reviewed and approved by Daily Board of the Medical Ethics Committee Erasmus MC. Written informed consent from the participants' legal guardian/next of kin was not required to participate in this study in accordance with the national legislation and the institutional requirements.

\section{AUTHOR CONTRIBUTIONS}

JS and RH contributed to conception and design of the study. CK organized the database, performed case study, and wrote the first draft of the manuscript. CK and $\mathrm{SH}$ performed data analysis. CK, $\mathrm{SH}$, JS, and RH drafted the manuscript for important intellectual content. JS, RW, and DT contributed to revising the manuscript and gave final approval. All authors contributed to the article and approved the submitted version.

\section{ACKNOWLEDGMENTS}

We thank Ko Hagoort for providing editorial advice.

\section{SUPPLEMENTARY MATERIAL}

The Supplementary Material for this article can be found online at: https://www.frontiersin.org/articles/10.3389/fped. 2021.660647/full\#supplementary-material 


\section{REFERENCES}

1. Peek GJ, Mugford M, Tiruvoipati R, Wilson A, Allen E, Thalanany MM et al. Efficacy and economic assessment of conventional ventilatory support versus extracorporeal membrane oxygenation for severe adult respiratory failure (CESAR): a multicentre randomised controlled trial. Lancet. (2009) 374:1351-63. doi: 10.1016/S0140-6736(09)61069-2

2. Morini, F, Goldman A, Pierro A. Extracorporeal membrane oxygenation in infants with congenital diaphragmatic hernia: a systematic review of the evidence. Eur J Pediatr Surg. (2006) 16:385-91. doi: 10.1055/s-2006-924751

3. Roberts TE. Economic evaluation and randomised controlled trial of extracorporeal membrane oxygenation: UK collaborative trial. The Extracorporeal Membrane Oxygenation Economics Working Group. BMJ. (1998) 317:911-5 doi: 10.1136/bmj.317.7163.911

4. Joshi V, Harvey C, Nakas A, Waller DA, Peek GJ, Firmin R. The need for thoracic surgery in adult patients receiving extracorporeal membrane oxygenation: a 16-year experience. Perfusion. (2013) 28:32832. doi: $10.1177 / 0267659113480401$

5. Taghavi S, Jayarajan SN, Mangi AA, Hollenbach K, Dauer E, Sjoholm LO, et al. Examining noncardiac surgical procedures in patients on extracorporeal membrane oxygenation. Asaio J. (2015) 61:520-5. doi: 10.1097/MAT.0000000000000258

6. Lally KP, Paranka MS, Roden J, Georgeson KE, Wilson JM, Lillehei CW, et al. Congenital diaphragmatic hernia. Stabilization repair on ECMO. Ann Surg. (1992) 216:569-73. doi: 10.1097/00000658-199211000-00008

7. Wilson JM, Bower LK, Lund DP. Evolution of the technique of congenital diaphragmatic hernia repair on ECMO. J Pediatr Surg. (1994) 29:110912. doi: $10.1016 / 0022-3468(94) 90289-5$

8. Sauer CM, Yuh DD, Bonde P. Extracorporeal membrane oxygenation use has increased by $433 \%$ in adults in the United States from 2006 to 2011. Asaio J. (2015) 61:31-6. doi: 10.1097/MAT.0000000000000160

9. Paden ML, Rycus PT, Thiagarajan RR, Registry E. Update and outcomes in extracorporeal life support. Semin Perinatol. (2014) 38:65-70. doi: 10.1053/j.semperi.2013.11.002

10. Barbaro RP, Paden ML, Guner YS, Raman L, Ryerson LM, Alexander P, et al. Pediatric extracorporeal life support organization registry international report 2016. Asaio J. (2017) 63:456-63. doi: 10.1097/MAT.0000000000000603

11. Atkinson JB, Kitagawa H, Humphries B. Major surgical intervention during extracorporeal membrane oxygenation. J Pediatr Surg. (1992) 27:11978. doi: 10.1016/0022-3468(92)90786-7

12. Keijzer R, Wilschut DE, Houmes RJ, van de Ven KP, van den Hout L, Sluijter I, et al. Congenital diaphragmatic hernia: to repair on or off extracorporeal membrane oxygenation? J Pediatr Surg. (2012) 47:6316. doi: 10.1016/j.jpedsurg.2011.11.016

13. Guzeltas A, Kasar T, Tanidir IC, Ozturk E, Yildiz O, Haydin S. Cardiac catheterization procedures in pediatric patients undergoing extracorporeal membrane oxygenation cardiac catheterization, ECMO. Anatol J Cardiol. (2017) 18:425-30. doi: 10.14744/AnatolJCardiol.2017.7927

14. Bond SJ, Lee DJ, Stewart DL, Buchino JJ. Open lung biopsy in pediatric patients on extracorporeal membrane oxygenation. J Pediatr Surg. (1996) 31:1376-8. doi: 10.1016/S0022-3468(96)90832-5

15. Inwald D, Brown K, Gensini F, Malone M, Goldman A. Open lung biopsy in neonatal and paediatric patients referred for extracorporeal membrane oxygenation (ECMO). Thorax. (2004) 59:328-33. doi: 10.1136/thx.2003.010793

16. Reiss I, Schaible T, van den Hout L, Capolupo I, Allegaert K, van Heijst A, et al. Standardized postnatal management of infants with congenital diaphragmatic hernia in Europe: the CDH EURO Consortium consensus. Neonatology. (2010) 98:354-64. doi: 10.1159/000320622

17. Van Meurs KP, Newman KD, Anderson KD, Short BL. Effect of extracorporeal membrane oxygenation on survival of infants with congenital diaphragmatic hernia. J Pediatr. (1990) 117:954-60. doi: 10.1016/S0022-3476(05)80144-1

18. Mugford M, Elbourne D, Field D. Extracorporeal membrane oxygenation for severe respiratory failure in newborn infants. Cochrane Database Syst Rev. (2008) CD001340. doi: 10.1002/14651858.CD001340.pub2

19. Schwartz S SJ, Kumar K, Bonadonna D, Hornik C, Turner D, Lodge A. Examining noncardiac surgical procedures in neonatal and pediatric patients on ECMO. Crit Care Med. (2018) 46:104. doi: 10.1097/01.ccm.0000528263.29456.0c

20. Houmes RJ, Ten Kate CA, Wildschut ED, Verdijk RM, Wijnen RM, de Blaauw I, et al. Risk and relevance of open lung biopsy in pediatric ECMO patients: the Dutch experience. J Pediatr Surg. (2017) 52:4059. doi: 10.1016/j.jpedsurg.2016.11.031

21. Bojanic K, Woodbury JM, Cavalcante AN, Grizelj R, Asay GF, Colby CE, et al. Congenital diaphragmatic hernia: outcomes of neonates treated at Mayo Clinic with and without extracorporeal membrane oxygenation. Paediatr Anaesth. (2017) 27:314-21. doi: 10.1111/pan.13046

22. Erdem O, Kuiper JW, Houmes RJ, van Ommen CH, van Rosmalen J, Tibboel $\mathrm{D}$, et al. Coagulation complications after conversion from roller to centrifugal pump in neonatal and pediatric extracorporeal membrane oxygenation. $J$ Pediatr Surg. (2020). doi: 10.1016/j.jpedsurg.2020.11.018. [Epub ahead of print].

23. IJsselstijn H, Hunfeld M, Schiller RM, Houmes RJ, Hoskote A, Tibboel D, et al. Improving long-term outcomes after extracorporeal membrane oxygenation: from observational follow-up programs toward risk stratification. Front Pediatr. (2018) 6:177. doi: 10.3389/fped.2018.00177

24. Dalton HJ, Reeder R, Garcia-Filion P, Holubkov R, Berg RA, Zuppa A, et al. Factors associated with bleeding and thrombosis in children receiving extracorporeal membrane oxygenation. Am J Respir Crit Care Med. (2017) 196:762-71. doi: 10.1164/rccm.201609-1945OC

25. Dalton HJ, Cashen K, Reeder RW, Berg RA, Shanley TP, Newth CJL, et al. Hemolysis during pediatric extracorporeal membrane oxygenation: associations with circuitry, complications, and mortality. Pediatr Crit Care Med. (2018) 19:1067-76. doi: 10.1097/PCC.0000000000001709

Conflict of Interest: The authors declare that the research was conducted in the absence of any commercial or financial relationships that could be construed as a potential conflict of interest.

Copyright (อ 2021 Kersten, Hermelijn, Wijnen, Tibboel, Houmes and Schnater. This is an open-access article distributed under the terms of the Creative Commons Attribution License (CC BY). The use, distribution or reproduction in other forums is permitted, provided the original author(s) and the copyright owner(s) are credited and that the original publication in this journal is cited, in accordance with accepted academic practice. No use, distribution or reproduction is permitted which does not comply with these terms. 